The Journal of Animal \& Plant Sciences, 30(5): 2020, Page: 1273-1282

ISSN (print): 1018-7081; ISSN (online): 2309-8694

\title{
STUDY OF BIOFILM RESPONSE OF OLEA EUROPAEA TO UV RADIATIONS: AN IN VITRO APPROACH
}

\author{
I. Liaqat ${ }^{* 1}$, N. M. Ali ${ }^{2}$, S. A. Mirza ${ }^{3}$, F. Ahsan ${ }^{4}$, A. A. Sardar ${ }^{3}$, H. M. Tahir ${ }^{1}$, S. Ali ${ }^{1}$, A. W. Qureshi ${ }^{5}$, U. Haneef ${ }^{3}$ and \\ M. Ulfat ${ }^{6}$ \\ ${ }^{* 1}$ Microbiology Laboratory, Department of Zoology, Govt. College University, Lahore-54000, Pakistan \\ ${ }^{2}$ Deaprtment of Zoology, Govt. College for Women, Model Town, Lahore \\ ${ }^{3}$ Department of Botany, GC University, Lahore \\ ${ }^{4}$ Department of Microbiology, University of Veterinary and Animal Sciences, Lahore \\ ${ }^{5}$ Department of Biology, Lahore Garrison University, Lahore, Pakistan \\ ${ }^{6}$ Department of Botany, Lahore College for Women University, Lahore, Pakistan \\ Corresponding author's email: iramliaq@hotmail.com
}

\begin{abstract}
A variety of bacteria, yeasts, and fungi colonize the aerial parts of plants termed as phyllosphere. Study of phylloshpere has gained considerable attention focusing on new non-invasive methods and bio-control agents of plant-associated microorganisms. The present study was designed to isolate microbes from phyllosphere of Olea europaea and assess their biofilm forming ability. Further, correlation between biofilm formation and ultraviolet (UV) radiation was observed. In total, four strains L1, L2, L3 and L4 were screened and purified from phyllosphere of O. europaea. Biochemical characterization and 16srRNA sequencing identified these strains as Erwinia herbicola (MN905123), Micrococcus luteus (MN905159), Pseudomonas syringae (MN905161) and Bacillus subtilis (MN905164). Physiological characterization revealed that strains exhibited optimum growth at $\mathrm{pH} 7$ and temperature $37^{\circ} \mathrm{C}$. Biofilm formation showed B. subtilis as the strongest biofilm former. Afterwards, UV radiation at various time intervals i.e., 3, 4, and 15 minutes indicated that bacterial biofilm was resistant upto 10 minutes UV exposure. A significant decrease ( $\mathrm{p} \leq 0.01$ ) in biofilm formation of mutant strains was observed after 15 minutes UV exposure thus pointing towards significantly reduced activity of the DNA repair gene. This study provided evidence that environments exposed to desiccation and/ ambient UV radiations could principally select for highly resistant microbial biofilms organisms against ionizing radiations, enabling these to withstand extreme conditions.
\end{abstract}

Keywords: O. europaea, Phyllosphere, Biofilms, UV mutation, Pathogenic bacteria.

https://doi.org/10.36899/JAPS.2020.5.0145

Published online June 25, 2020

\section{INTRODUCTION}

The aerial parts of plants are generally inhabited by various types of fungi, bacteria and yeasts. Few microbial species can be isolated from within the plant tissues while some are normally obtained from even healthy plant surfaces. Microbial colonization on the aerial parts of plant called as epiphytes and their potential role for pollution remediation and plant growth demands for in depth investigation of their community and diversity (Espenshade et al., 2019). The leaf microbial communities (Epiphytes) differ greatly in size and number among and within plants of same species over short period of time as well as over the growing season. This bacterial diversification may be due to variable physical and nutritional conditions prevailing in phyllosphere (Bringel and Couée, 2015). It is also evident that they play an important role in biogeochemical cycling and this role varies in biofilm mode (Bridier et al., 2017).
Leaf surface represent a biological desert due to direct exposure to harsh environmental conditions, ultraviolet (UV) radiation, drought and high fluctuations of daily temperature (de Oliveira et al., 2019). Microbes present on the leaf surface are also directly exposed to UV radiation, but it doesn't affect their high colonization ability. Irreversible and cytotoxic damage caused by UV results in formation of thymine-thymine dimers. Microbial community on leaf has evolved various molecular mechanisms to protect their DNA (Sinha and Hader, 2002). Among these, significantly reported one is their ability of biofilm formation. It has reported that bacterial strategy to biofilm formation is their ability to increase the activity of DNA repair gene, hence preventing UV damage (Balint-Kurti et al., 2010). Additionally, UV effect on leaf is counterbalanced by protection strategies both by plants and epiphytes. These include photochemical quenching, production of UV absorbing compounds (i.e., flavones and flavones glycosides, scytonemin (cyanobacteria) and phlorotannins), shading by carbonate layers, 
morphological changes, changing pigment contents, downregulation of photosystem II and chloroplast clumping (Sharon et al., 2011).

Olea europaea (Olive) is the oldest cultivated plant in world. It is good source of edible oil. The nutritional and medicinal value alongwith free fat content is ideal for health. It is particularly used in textile industry, food preservation, and various cosmetic purposes (Bracci et al., 2011). Relatively little research has been conducted on phyllosphere microbiology in contrast to other bacterial colonized surfaces. Until now only a few genera of culturable bacteria have been found to dominate the phyllosphere (Müller et al., 2015). Preliminary results from biofilm abundance in phyllosphere indicated that biofilm bacteria constitute between about 10 to $40 \%$ of bacterial population on leaves of $O$. europaea (Bracci et al., 2011) following different methods used to quantify its formation (Edziri et al., 2019). Keeping in view the importance of this crop and phyllosphre significance, this study was designed to investigate microbial population of $O$. europaea and analyse its biofilm formation. Additionally, a correlation between biofilm formation and UV exposure was monitored to understand plant strategies to cope with harsh conditions.

\section{MATERIALS AND METHODS}

Sampling of Plant material: This study was performed in Microbiology Laboratory, Department of Zoology, GC University, Lahore -. Sampling of leaves from $O$. europaea (Voucher $\mathrm{No}=\mathrm{GC}$.Herb.Bot.2742) was done from plants at the National Agricultural Research Centre (NARC), Islamabad.

Bacterial strains isolation and purification: $2.5 \mathrm{~g}$ leaves of $O$. europaea were washed with phosphate buffer saline (PBS) for 5 minutes by shaking at $120 \mathrm{rpm}$. Afterwards, leaves were removed and rinsed with sterile PBS. Both suspensions were mixed and $10 \mathrm{ml}$ from the original wash was plated on nutrient agar. Strains were isolated and purified after multiple rounds of streaking and restreaking. Following Bergey's manual of systemic bacteriology, isolated strains were characterized on the basis of cell shape, arrangement, size, motility, gram staining and capsule staining. Gram staining shows the major differences between the Gram positive and Gram negative cell walls on the basis of peptidoglycan (a carbohydrate), teichoic acid and lipopolysaccharides (LPS). Gram positive bacteria appear purple and Gram negative as red after staining performed. Capsule staining is used to identify the presence of thick and firmly attached polysaccharide-rich structure (glycocalyx) external to the cell wall called capsule. It is also called as negative staining since background (the slide) and the bacteria are stained, but the capsule is not stained. The capsule appears as a clear unstained zone around the bacterial cell. Endospore staining was performed after one week incubation at $37^{\circ} \mathrm{C}$. It is used to stain endospore which is the survival mechanism of the mostly Gram positive bacterial species such as Clostridium and Bacillus as well as other species. Purified isolated colonies were further characterized on MacConkey agar (Sigma), blood agar (Merck) and chocolate agar (Oxoid CM55) following Gerhardt et al. (1994).

Biochemical Characterization and 16srRNA Sequencing: Biochemical tests including catalase, citrate utilization, indole, tryptophan deaminase, methyl red, $\mathrm{H}_{2} \mathrm{~S}$ production, voges proskauer and urease were performed to characterize bacterial strains (Gerhardt et al., 1994). Physiological characterization was done on the basis of growth curve, variable temperatures $\left(25^{\circ} \mathrm{C}, 37^{\circ} \mathrm{C}\right.$ and $\left.50^{\circ} \mathrm{C}\right)$ and $\mathrm{pH}(5,7,9$ and 12). 16S rRNA gene sequencing was performed using forward primer (16S27F 5'-AGAGTTTGATCCTGGCTCAG-3') and reverse primer $\quad\left(16 \mathrm{~S}-1522 \mathrm{R} \quad 5^{\prime}\right.$ AAGGAGGTGATCCAGCCGCA-3') (Liaqat et al., 2016). PCR reaction mixture consists of $10 \times$ PCR Buffer $5 \mu l, 4 \times$ dNTPs $(10 \mathrm{mmol} / l) 4 \mu l$, TaqDNA polymerase (5 U/ $\mu l$ ) $0.5 \mu l$, upstream and downstream primer (concentration, $50 \mu \mathrm{mol} / l$ ) each $1 \mu l$, template $1 \mu l$, and ultra-pure water to a final volume of $50 \mu l$. The reaction conditions were: $95^{\circ} \mathrm{C}$ denaturation for $5 \mathrm{~min}, 35$ cycles of $94^{\circ} \mathrm{C}$ denaturation $1 \mathrm{~min}, 53-55^{\circ} \mathrm{C}$ annealing $1 \mathrm{~min}$, $72^{\circ} \mathrm{C}$ extension $1 \mathrm{~min}$ and a final extension at $72^{\circ} \mathrm{C}$ for 10 min. The PCR products were gel purified, sequenced and analysed using Chromas Lite software.

Biofilm Formation: Biofilm formation was assessed using two methods. In first method, Congo red medium was prepared to culture isolated bacteria followed by incubation for 24 hours at $37^{\circ} \mathrm{C}$. Black colony formation indicated biofilm formation ability (Liaqat et al., 2016). For air liquid interface cover slip assay, biofilm formation was analyzed by measuring bacteria attached to the cover slips under light microscope (Data not shown). Quantification of biofilm was done by dissolving crystal violet stained attached cell mass in 33\% acetic acid and O.D measurement at $523 \mathrm{~nm}$ (Liaqat et al., 2016).

Construction of Mutants by UV Exposure: Modification of Miller's protocol (1992) was applied to induce mutation in isolated strains via UV irradiation. The UV irradiation was carried out by placing cell suspension in laminar flow cabinet and exposing for 5, 10 and 15 minutes. About $100 \mu 1$ of each suspension from control and mutant strains was plated and incubated in dark for 24 hours at $37^{\circ} \mathrm{C}$. Viable colonies were counted. Afterwards, motility and biofilm formation of mutant strains was analysed as mentioned in above section. 
Statistical Analysis: Data regarding growth curve, $\mathrm{pH}$ and temperature was analysed and presented as mean and sem. Using the statistical software SPSS Version 15.0 (Windows Evaluation Version), one way ANOVA followed by post hoc Turkey was used to determine the effect of $U V$ radiations on bacterial biofilms $(\mathrm{P}<0.05)$.

\section{RESULTS AND DISCUSSION}

The phyllosphere, dominated by photosynthetic leaves, comprises of plant aerial parts and is one of the most important microbial habitats in ecosystem. Phyllosphere microbiology has gained considerable attention due to various natural processes taking place between plants, atmosphere and microbial life. It is an area of deep and merging concern with aim to identify, and investigate host evolutionary relatedness and adaptability of plant functional traits to host ecological strategies for resource nurturing and growth/mortality tradeoffs (Guo et al., 2014). This study was performed to isolate and identify bacteria from phyllosphere of $O$. europea. Furthermore, their biofilm forming ability as well as the correlation between biofilm formation and UV radiations was investigated.

First objective of the study was to isolate and identify culturable organisms from $O$. europea leaf surface. Among 25 isolates, a total of four strains were purified. Morphological characterization showed variations in size, margin and elevation. Some strains were glistering, smooth, round, regular and elevated, while others were mucoid, small, and round (Table 1). Two strains (L3, L4) were Gram's positive and others two (L1, L2) were Gram negative. Except for L3, all strains were motile (Table 2). Biochemical characterization revealed that all strains observed in this study were catalase positive. Three of the strains (L2, L3 and L3) were citrate positive, using citrate as sole carbon. All strains were negative for methyl red test except for L1 indicating their ability to catabolize glucose. Only one (L1) strain showed positive result for indole test. Three of the strains (L2, L3 and L4) were urease positive. All strains showed growth on blood agar without any hemolysis (Data not shown). Allegrucci and Sauer (2007) observed similar morphological and biochemical variations in strains isolated from biofilms. Next, we performed 16S rRNA gene sequencing to identify the strains upto species level. 16S rRNA gene sequencing is a more convincing method to identify bacteria upto species level, giving us an opportunity to recognize even novel and noncultured bacteria (Yang et al., 2001). It was observed that isolated strain LI was closely related to Erwinia herbicola, L2 with Micrococcus luteus, L3 with Pseudomonas syringae and L4 with Bacillus subtilis. These were registered in the GenBank Database with the accession numbers MN905123, MN905159, MN905161 and MN905164 respectively. Finally, a phylogenetic tree was constructed using MEGA 10 software and the genetic distance of each strain was determined (Fig. 1). Similar findings were reported by Koh et al. (2007), previously, who observed that epiphytic bacterial community was highly diverse and largely composed of $P$. syringae followed by other less dominant strains including strains belonging to Bacillus and Micrococcus species.

Following 16S rRNA gene sequencing, physiological characterization of four identified strains was performed by monitoring growth, temperature and $\mathrm{pH}$. Growth curve kinetic indicated that isolated bacteria showed variations in lag, log and stationary phase in this study. E. herbicola showed 4 hour long lag phase followed by 4 hour log phase and 2 hours stationary phase. $P$. syringae exhibited a 3 hours lag phase, 4 hours $\log$ phase followed by 3 hours stationary phase. Likewise, in $M$. luteus, growth curve data showed lag phase of 2 hours, $\log$ phase of 5 hours and stationary phase of 4 hours. In case of B. subtilis, 5 hours long log phase followed by 3 hours long stationary phase was observed (Fig. 2). Decline after 18 hours growth phase observed in most strains in this study might be due to depleted nutrients with passage of time particularly due to strains growth in batch culture (Liaqat et al., 2009). Though, isolates showed growth over a wide range of $\mathrm{pH}(5,7,9$, and 12). However, best growth was observed at $\mathrm{pH} 7$, showing detrimental effect of acidic $\mathrm{pH}$ (Fig. 3). This also indicates that isolated strains were alkaliphilic and their survival in the medium might be due to presence of abundant amino acids as well as carbohydrates in their cell walls (De Lemos Esteves et al., 2005). Regarding temperature, all strains were mesophilic, preferring $37^{\circ} \mathrm{C}$ for best growth (Fig. 4). Below this temperature, enzymatic activity of isolated strains might be decreased hence affecting the rates of enzyme catalyzed reactions. This results in reducing the metabolic functions by abruptly dispersing cellular components (Yang and Zhou, 2004). The isolation of variety of bacteria belonging to different genera on phyllosphere of $O$. europaea showed their ability to tolerate a wide range of environmental conditions (Yang and Zhou, 2004).

Phyllosphere bacteria use a variety of methods to adopt themselves to changing environments. Often, they protect themselves by secreting extracellular polymeric substances (EPS) enclosed communities called biofilms and thus preventing excessive UV exposure and extreme evaporation (Pointing et al., 2007). Congo red method was initially chosen to assess qualitative biofilm formation in all four bacteria. It was observed that only one strain $(25 \%)$ B. subtilis had biofilm forming ability as showed by black crystalline morphology (Fig. 5). This led us to use liquid interface cover slip assay, a more reliable method (Liaqat et al., 2009) for monitoring biofilm forming potential of isolates. Interestingly, using this assay, we observed that all isolates have ability to 
adhere and form robust biofilm on glass surfaces. Bacteria on leaf surface produce biofilm to protect against harsh environment including UV damage. Previous studies have shown that biofilm formation is a common phenomenon prevalent in both Gram positive and Gram negative bacteria (O'Toole and Kolter, 1998; Liaqat et al., 2009). However, B. subtilis was observed to be the best biofilm former on glass surfaces. The highest biofilm formation was observed in $B$. subtilis followed by
P. syringae, M. luteus and E. herbicola. A decrease in biofilm formation was observed after 24 hours in all isolates (Fig. 6). The highest biofilm formation observed in B. subtilis might be due to increased EPS production. Davey and O'Toole (2000) reported that EPS protect cells from UV radiation, osmotic shocks and diversified $\mathrm{pH}$. It forms a highly hydrated layer surrounding bacterial colonies and thus protect against desiccation/drying (Monier and Lindow, 2003).

Table 1. Colony morphology of bacterial strains isolated from phyllosphere of $O$. europaea.

\begin{tabular}{|c|c|c|c|c|c|c|}
\hline Strains & Shape & Color & Margin & Elevation & Optical characters & Texture \\
\hline L1 & Circular & Yellow & Entire & Raised & Translucent & Moist \\
\hline L2 & Circular & Off White & Irregular & Raised & Transparent & Dry \\
\hline L3 & Circular & Yellow & Entire & Convex & Opaque & Dry \\
\hline L4 & Circular & White & Irregular & Convex & Opaque & Dull \\
\hline
\end{tabular}

Table 2. Growth of bacterial strains isolated from phyllosphere of $O$. europaea on different media.

\begin{tabular}{ccccccc}
\hline Strains & Blood agar & EMB & Gram Staining & Endospore Staining & Capsule Staining & Motility Test \\
\hline L1 & $\Gamma$ & - & - & - & - & + \\
L2 & B & - & - & $\mp$ & + \\
L3 & $\Gamma$ & - & + & $\mp$ & - & + \\
L4 & $\Gamma$ & + & + & - & + \\
\hline
\end{tabular}

Table 3. Biochemical tests of bacterial strains isolated from phyllosphere of $O$. europaea.

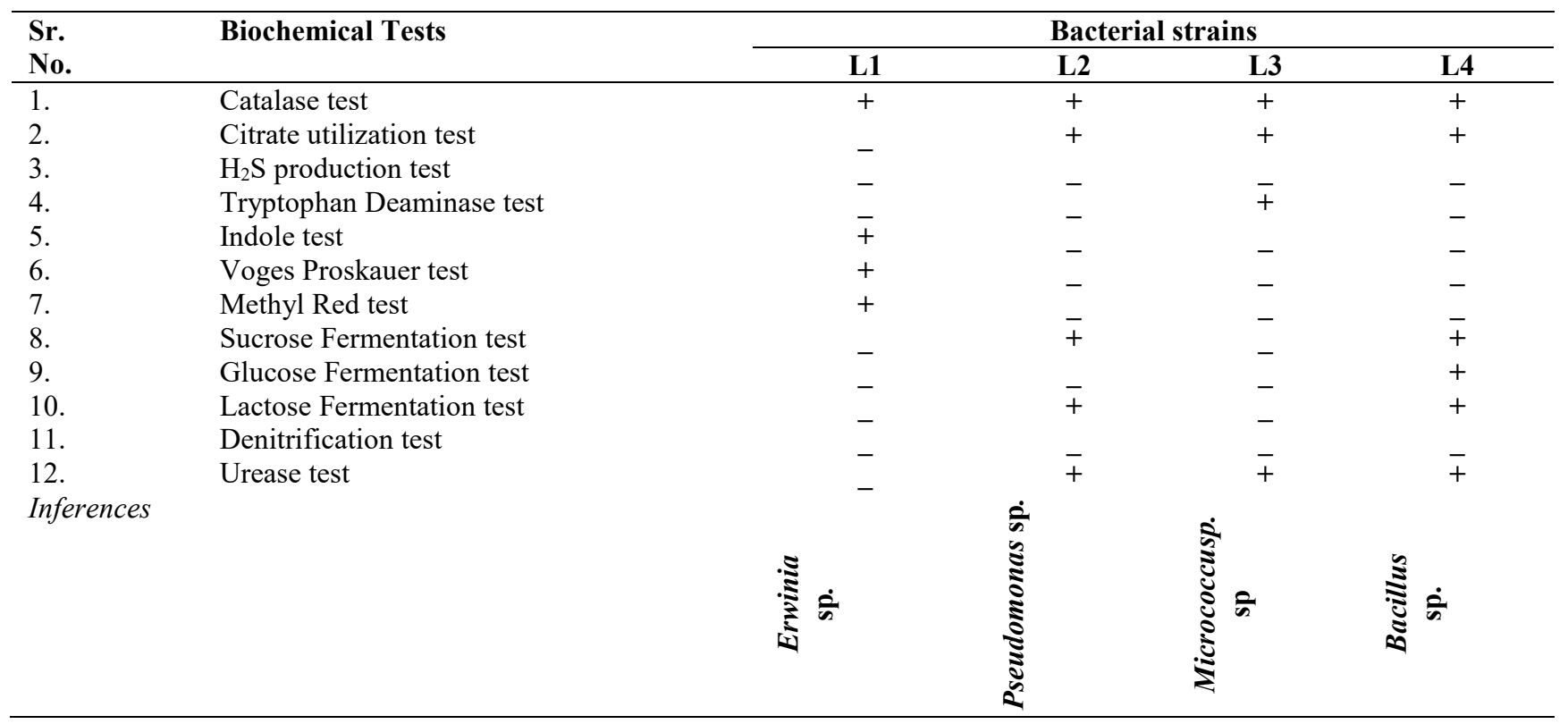

Plant canopy provides shade to underlying leaves, however, bacteria present on leaves use various ways such as biofilm production, chromophores production etc. to protect against damaging UV radiation. While studying effect of UV radiations on bacterial biofilm, we observed that UV radiations resulted in biofilm reduction in all four strains including $E$. herbicola, M. luteus, P. syringae and B. subtilis. Non- significant reduction $(\mathrm{p} \leq 0.05)$ in biofilm formation was observed in mutant strains after 5 and 10 minutes of UV exposure compared to wild type (Figs. 7-8) . While, highly significant reduction $(\mathrm{p}<0.001)$ in biofilm formation of isolated strains was observed after 15 minutes of UV exposure (Fig. 9). B. subtilis was observed to be most resistant strain against $\mathrm{UV}$ radiations, while $E$. herbicola showed minimal resistance. Sinha and Hader 
(2002) reported that different bacteria modify their genetic machineries in different ways to control their
DNA integrity thus escaping cytotoxic andirreversible DNA damage.

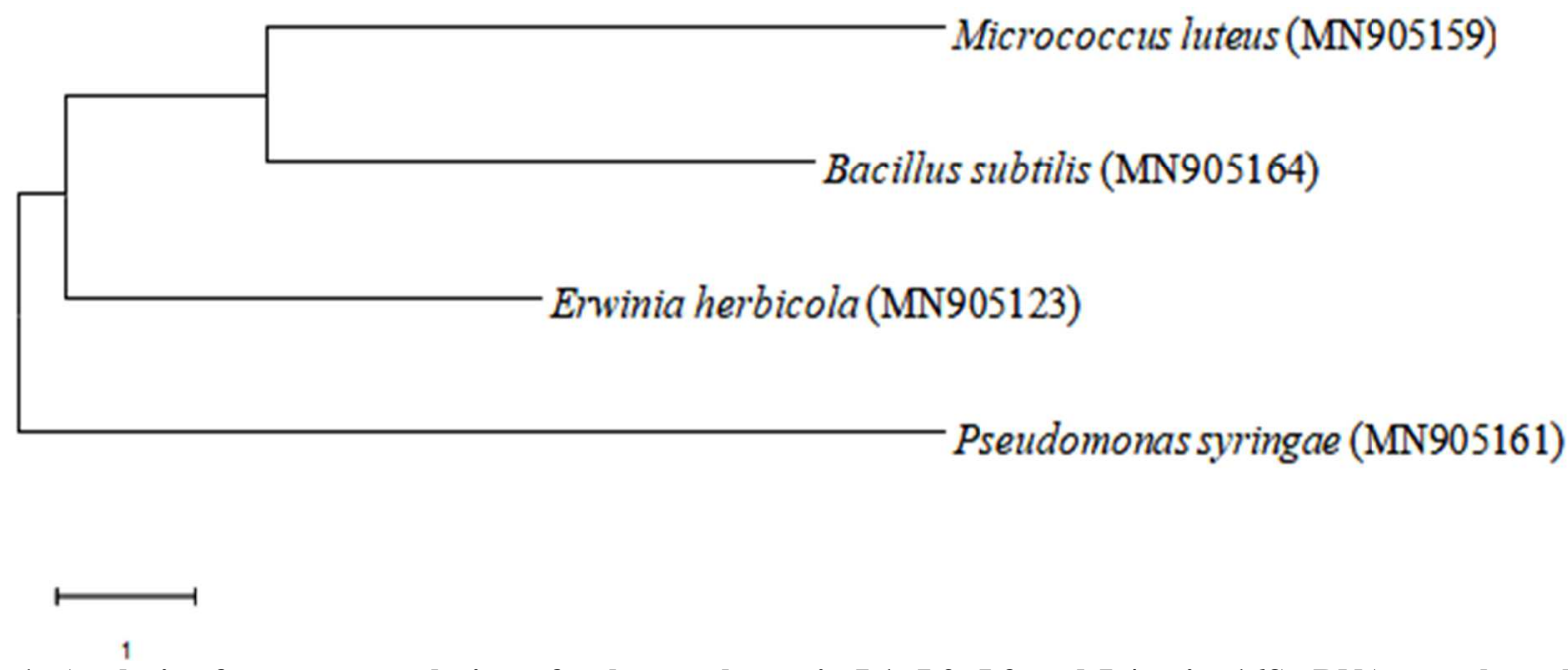

Fig. 1. Analysis of sequence evolution of unknown bacteria L1, L2, L3 and L4 using16S rRNA gene homology. Phylogenetic tree was constructed using MEGA 10 software and the genetic distance of each strain was determined.

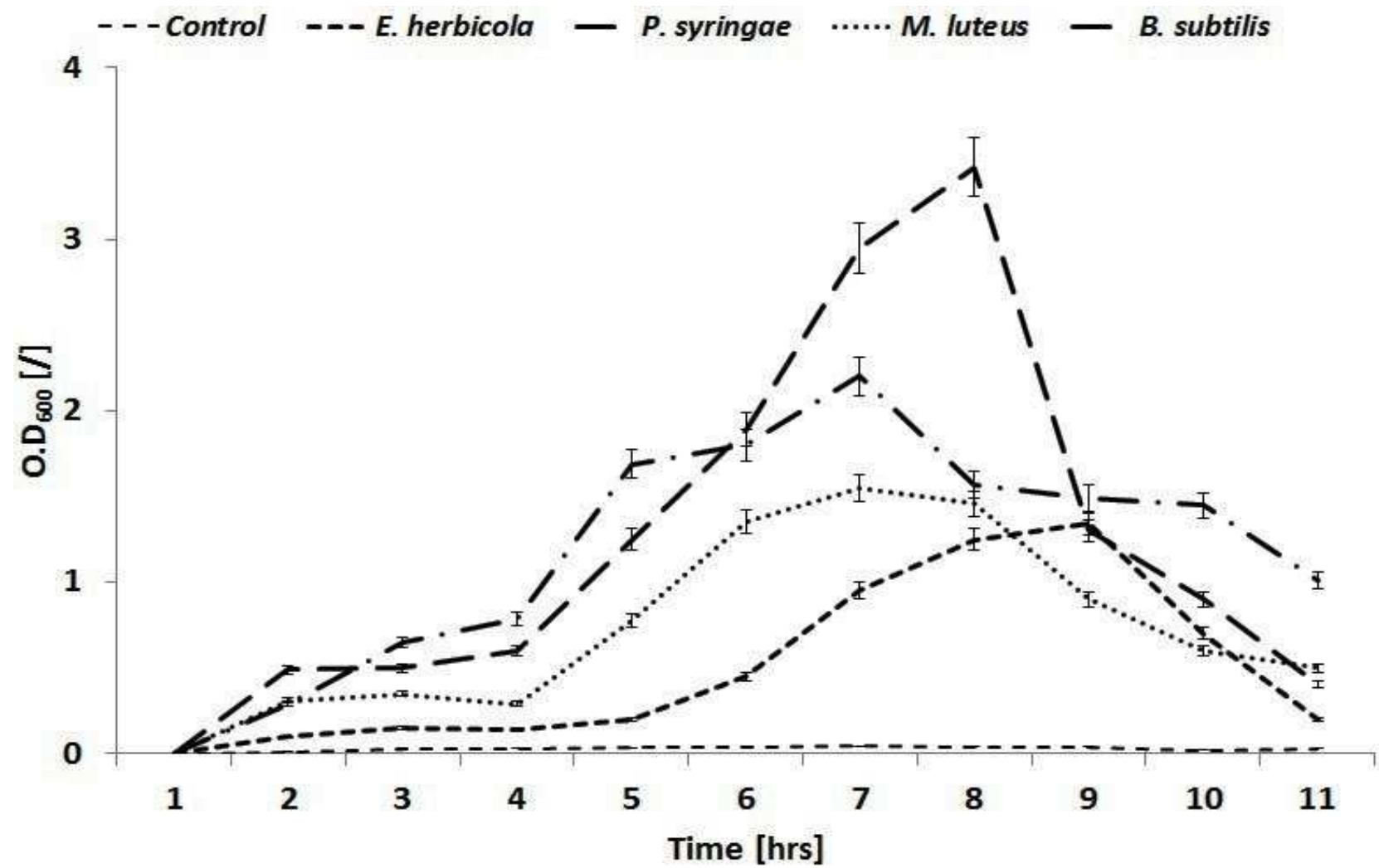

Fig. 2. Growth curve of bacterial strains (E. herbicola, P. syringae, M. luteus and B. subtilis) isolated from minimally processed fruit of $O$. europaea. Bacteria were grown in LB medium over a period of 12 hours. OD $_{600}$ was measured at respective time intervals. Data obtained was average of three independent experiments. 

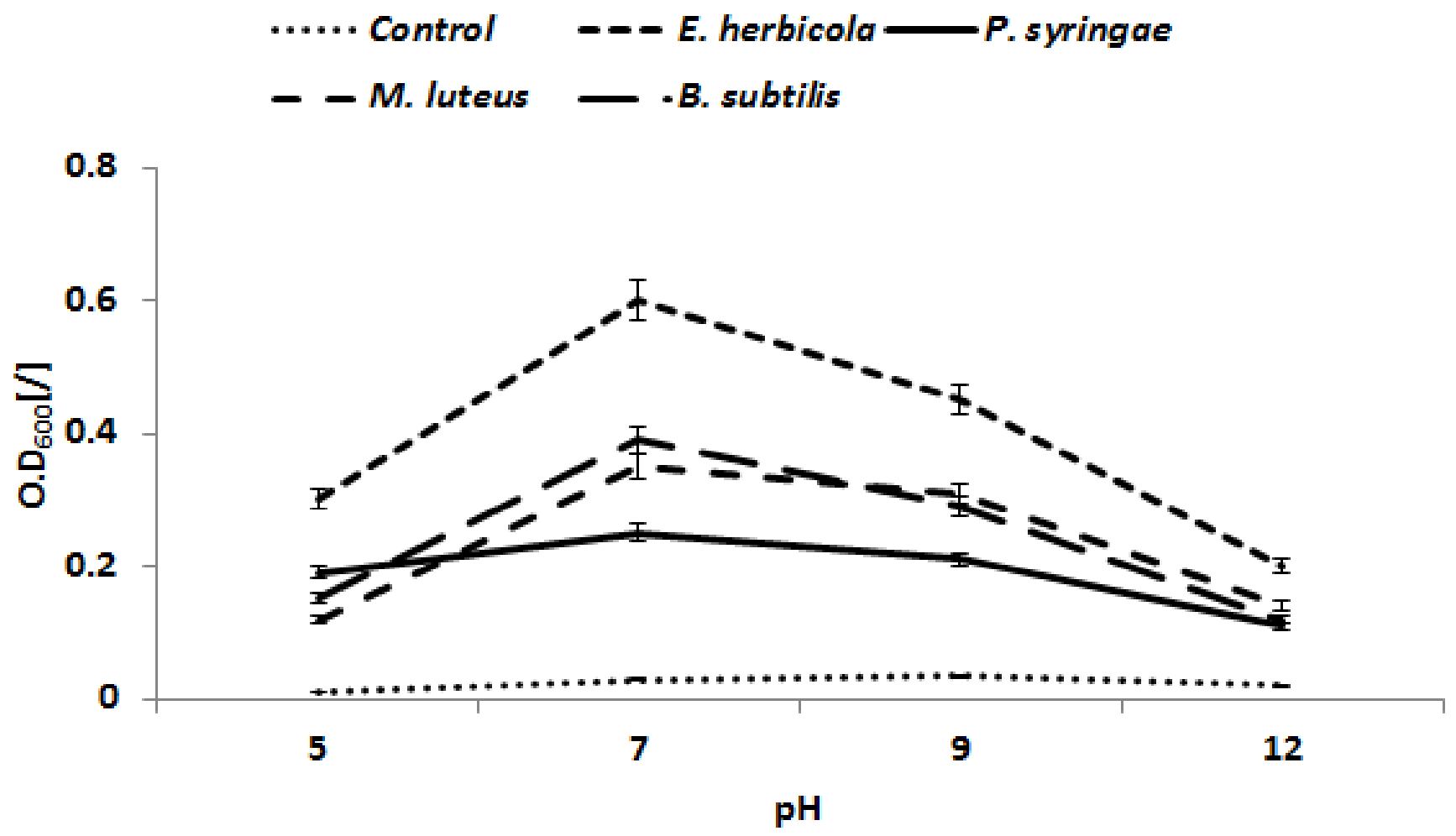

Fig. 3. Effect of pH on bacterial strains. Bacterial strains (E. herbicola, $P$. syringae, M. luteus and $B$. subtilis) were isolated from minimally processed fruit of $O$. europaea. Bacteria were grown in LB medium over a period of 12 hours at various pH $(5,7,9$ and 12). OD600 was measured and Data obtained was average of three independent experiments.

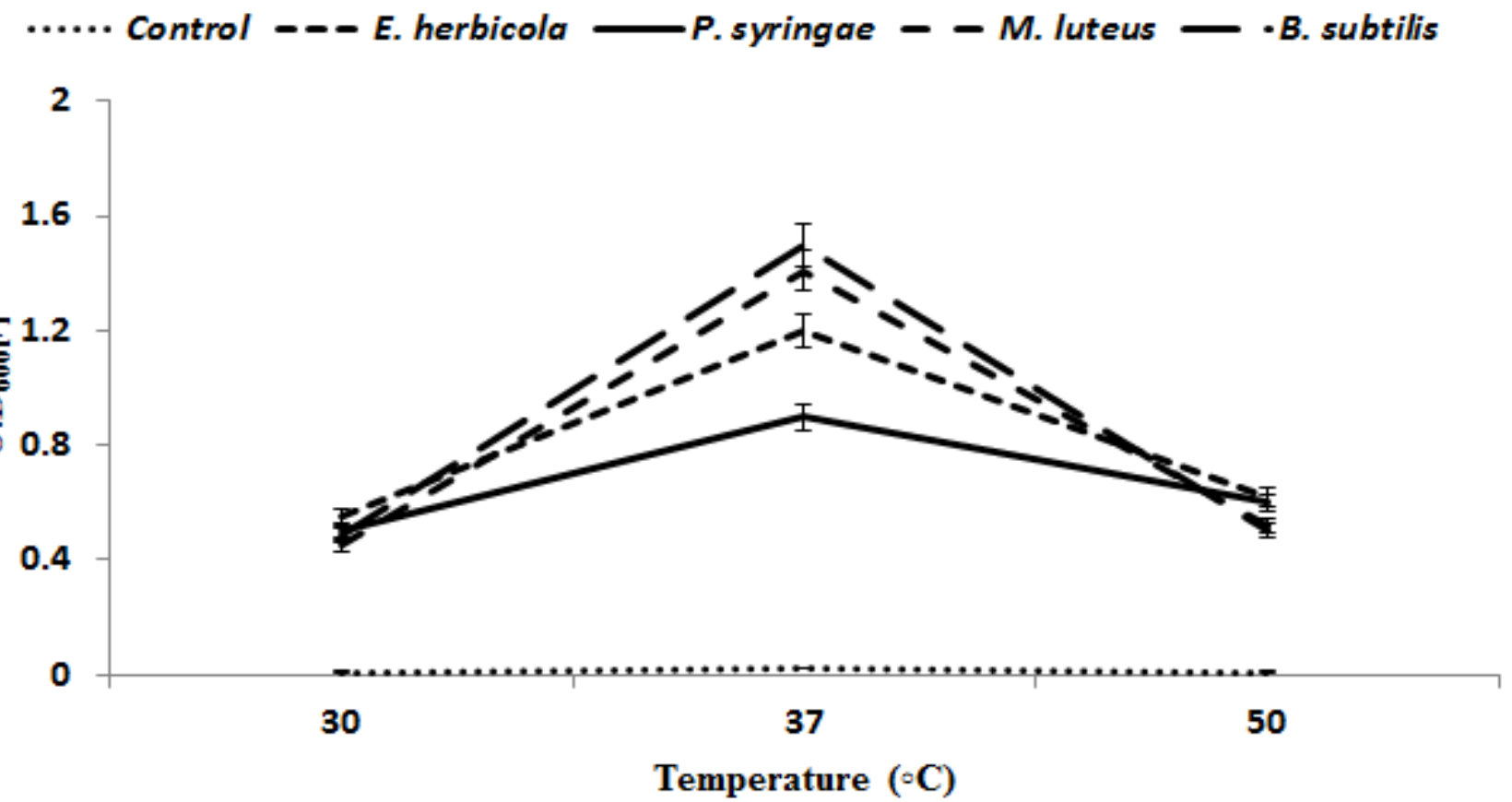

Fig. 4. Effect of temperature on bacterial strains. Bacterial strains (E. herbicola, P. syringae, M. luteus and B. subtilis) were isolated from minimally processes fruit of $O$. europaea. Bacteria were grown in LB medium over a period of 12 hours at various temperatures $\left(30,37\right.$ and $\left.50^{\circ} \mathrm{C}\right)$. OD $_{600}$ was measured and data obtained was average of three independent experiments. 


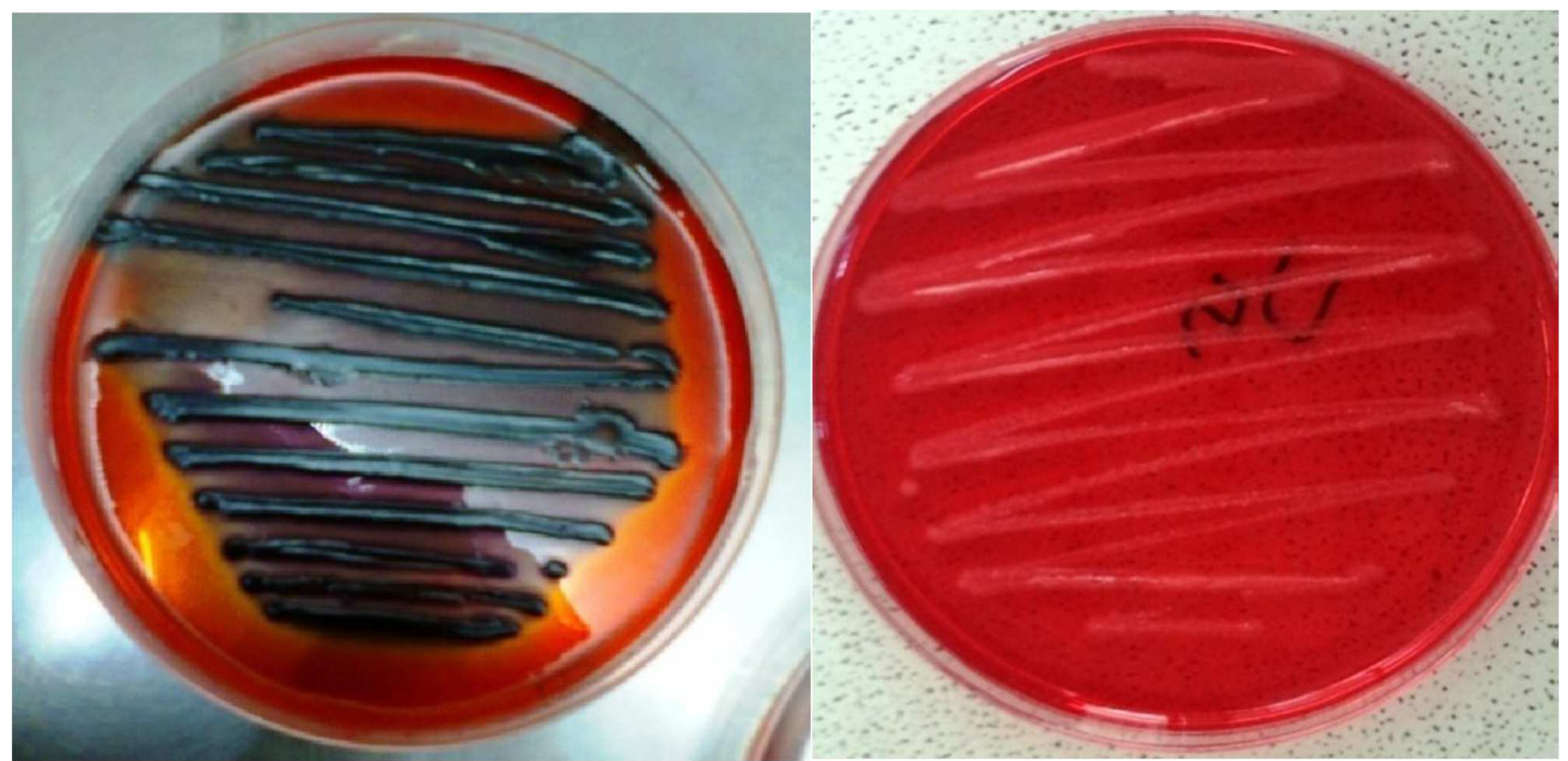

Fig. 5. Biofilm formation by Congo red method: a) Black coloration produced by $B$. subtilis showed positive results b) Red coloration by $P$. syringae showed negative results.

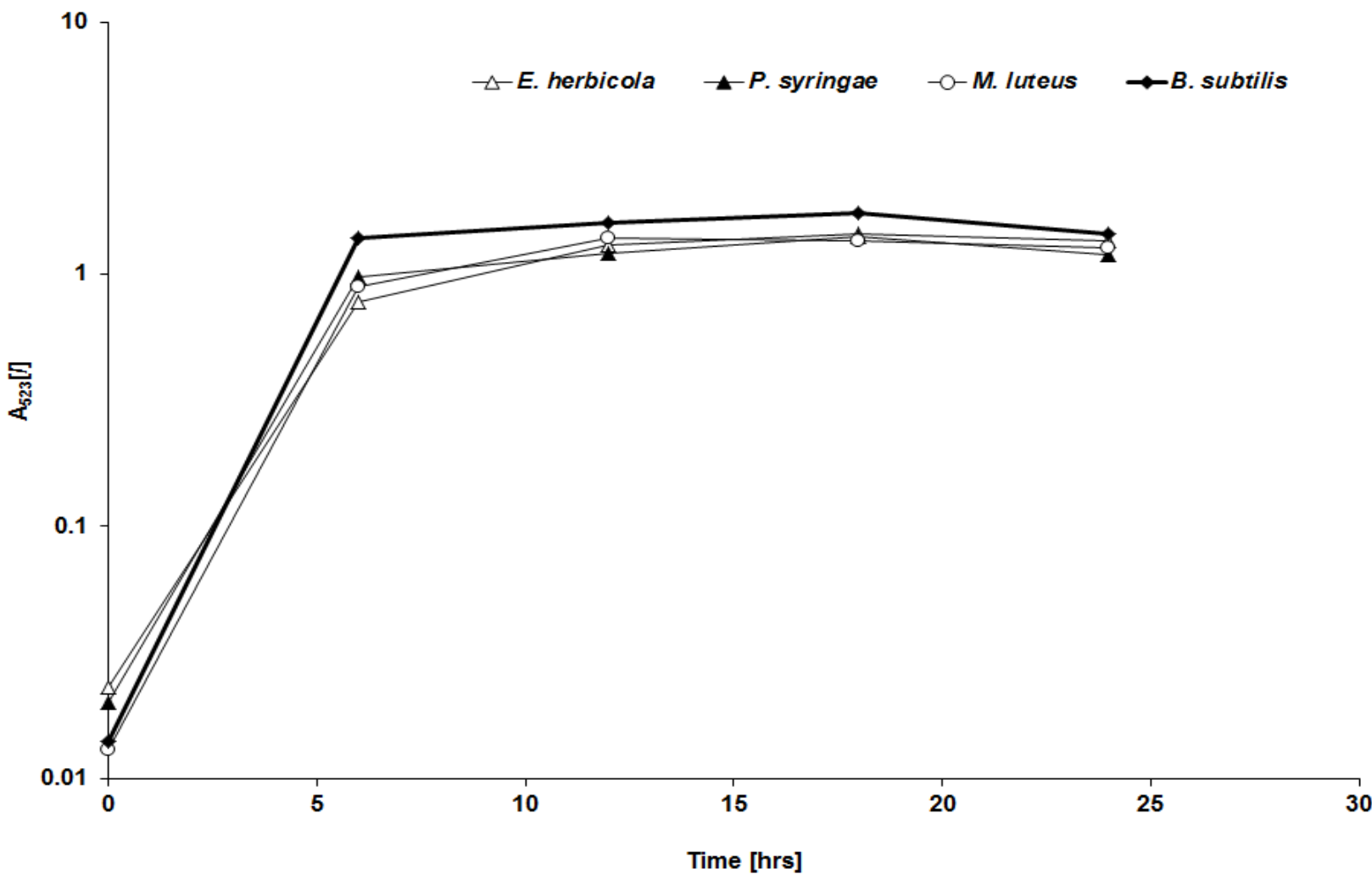

Fig. 6. Time course of biofilm formation assay by four strains (E. herbicola, $P$. syringae, M. luteus and $B$. subtilis) Bacteria were grown overnight and diluted in fresh LB medium assayed for biofilm formation at 06,12 and 18 and 24 hours. Data was obtained from average of three independent experiments. 


\section{Wild Type Mutant}

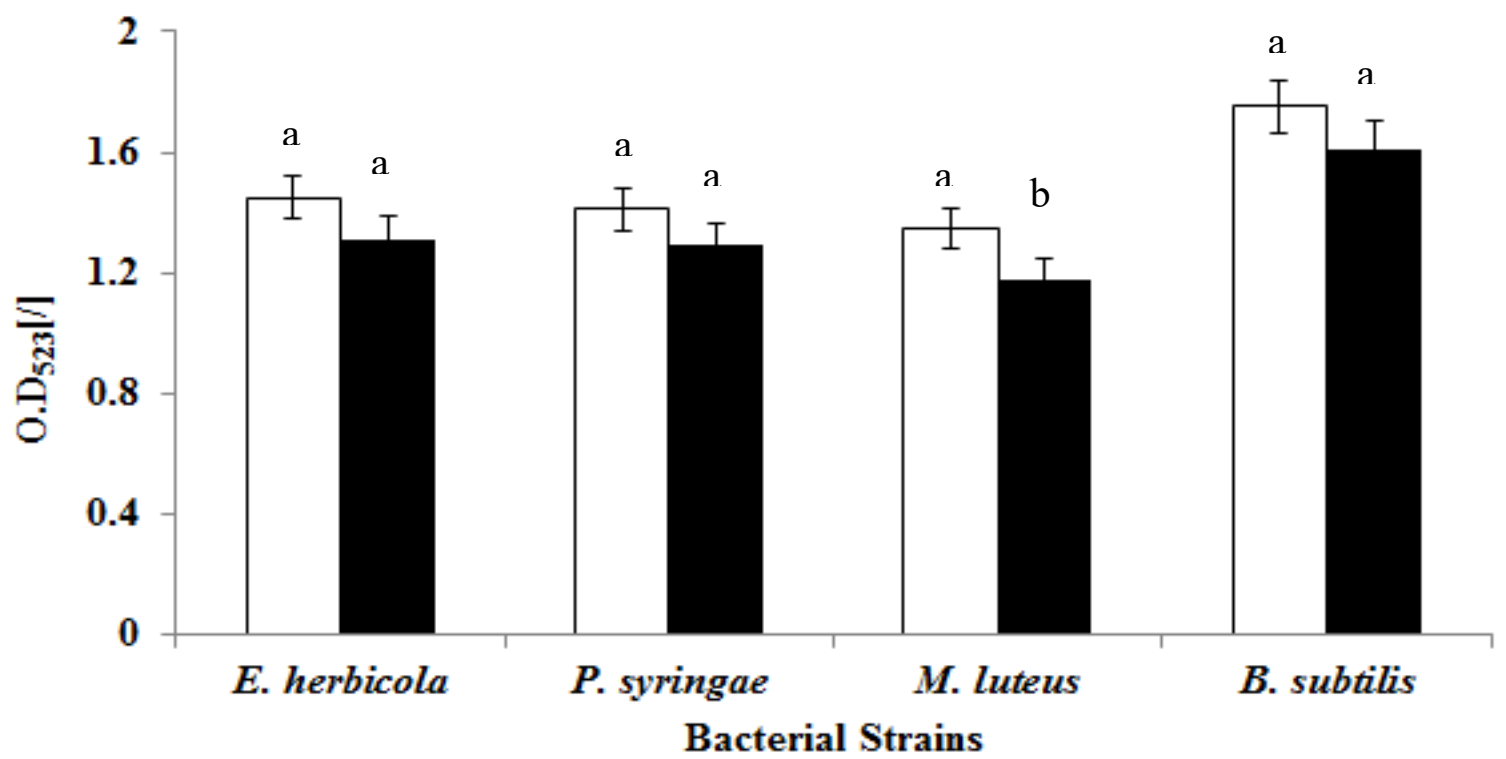

Fig. 7. Effect of UV radiations on biofilm formation. Bacterial strains (E. herbicola, P. syringae, M. luteus and $B$. subtilis) were exposed to UV light for 5 minutes. Quantification of biofilm was done at 523 nm. Data was obtained from average of three independent experiments. One-way analysis of variance (ANOVA) with post hoc Turkey was used to determine the independent effect of $U V$ irradiation on the different strains. Bars with different superscript are significantly different at $\mathbf{P} \leq \mathbf{0 . 0 5}$.

$\square$ Wild Type $\square$ Mutant

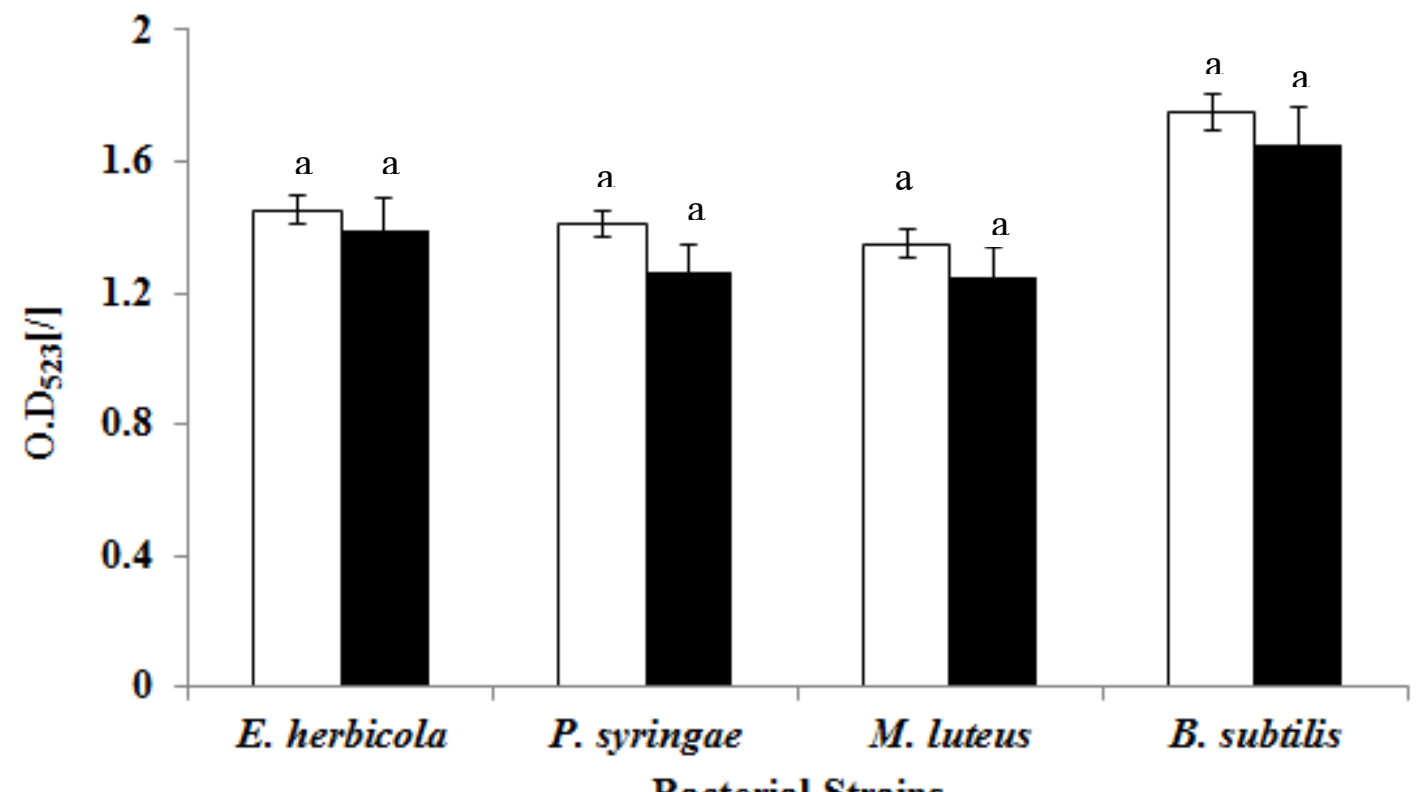

Fig. 8. Effect of UV radiations on Biofilm Formation. Bacterial strains (E. herbicola, P. syringae, M. luteus and B. subtilis) were exposed to UV light for 10 minutes. Quantification of biofilm was done at $523 \mathrm{~nm}$. Data was obtained from average of three independent experiments. One-way analysis of variance (ANOVA) with post hoc Turkey was used to determine the independent effect of UV irradiation on the different strains. Bars with different superscript are significantly different at $\mathbf{P} \leq \mathbf{0 . 0 5}$. 


\section{Wild Type $\quad$ Mutant}

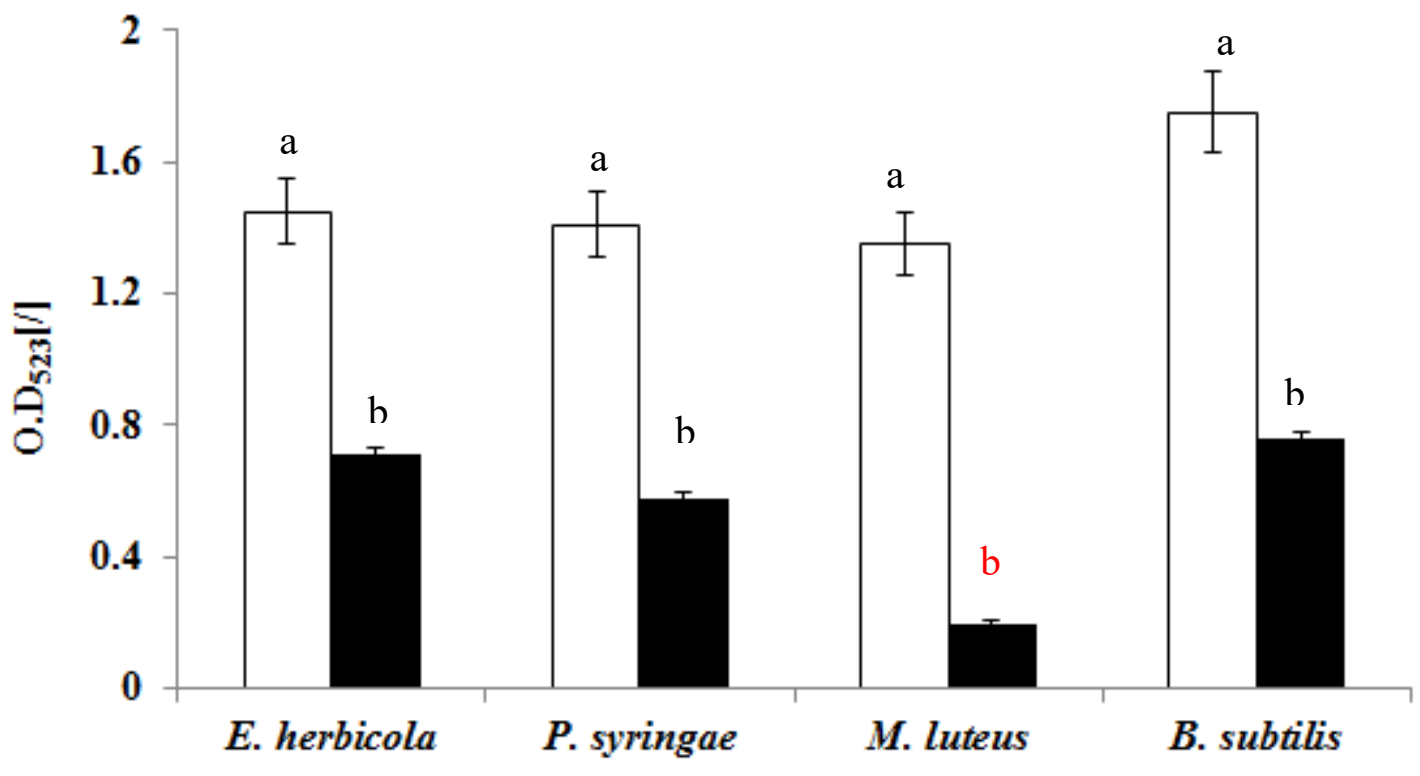

Bacterial Strains

Figure 9. Effect of UV radiations on Biofilm Formation. Bacterial strains (E. herbicola, P. syringae, M. luteus and $B$. subtilis) were exposed to UV light for 15 minutes. Quantification of biofilm was done at $523 \mathrm{~nm}$. Highly significantly reduced biofilm was observed by mutant strains compared to wild type. Data was obtained from average of three independent experiments. One-way analysis of variance (ANOVA) with post hoc Turkey was used to determine the independent effect of UV irradiation on the different strains. Bars with different superscript are significantly different at $\mathrm{P} \leq \mathbf{0 . 0 5}$.

Conclusions: The phyllosphere is an important habitat to study microbial ecology from both scientific and economic perspective. Isolated microbes and their biofilm formation study will have important practical applications to better understand communication as well as interactions among plant and microbes. Furthermore, correlation between leaf microbial biofilm and UV radiations provided evidence that biofilm communities growing in sunlight exposed areas are well adapted to high levels of ionizing radiations such as UV radiations, hence enabling them to withstand changing environmental conditions.

Author's contribution: IL planned the study. IL, NM Ali, SA Mirza, F Ahsan guided the experimental protocols. AA Sardar, HM Tahir, S Ali, AW Qureshi helped in analyzing the data. IL, U Haneef and M Ulfat wrote the manuscript. All authors revised the manuscript and approved the content of manuscript.

\section{REFERENCES}

Allegrucci, M. and K. Sauer (2007). Characterization of colony morphology variants isolated from Streptococcus pneumoniae biofilms. J. Bacteriol. 189 (5): 2030-38.
Balint-Kurti, P., S.J. Simmons, J.E. Blum, C.L. Ballaré, and A.E. Stapleton (2010). Maize leaf epiphytic bacteria diversity patterns are genetically correlated with resistance to fungal pathogen infection. Mol. Plant. Microbe. Interact. 23: 473484.

Bracci, T., M. Busconi, C. Fogher, and L. Sebastiani (2011). Molecular studies in olive (Olea europaea L.): overview on DNA markers applications and recent advances in genome analysis. Plant. Cell. Rep. 30(4): 449-462.

Bridier, A., J.C. Piard, C. Pandin, S. Labarthe, F. DuboisBrissonnet, and R. Briandet (2017). Spatial organization plasticity as an adaptive driver of surface microbial communities. Front Microbiol. 8: 1364.

Bringel, F. and I. Couée (2015). Pivotal roles of phyllosphere microorganisms at the interface between plant functioning and atmospheric trace gas dynamics. Front. Microbiol. 6: 486.

Davey, M.E. and G.A. O'toole (2000). Microbial biofilms: from ecology to molecular genetics. Microbiol. Mol. Biol. Rev. 64(4): 847867.De Lemos E.F., T. Gouders, J. LamotteBrasseur, S. Rigali, and J.M. Frère (2005). Improving the alkalophilic performances of the Xyll xylanase from Streptomyces $s p$ S38: 
structural comparison and mutational analysis. Protein Sci. 14(2): 292-302.

De Lemos Esteves, F., T. Gouders, J. Lamotte-Brasseur, S. Rigali, and J.M Frère (2005). Improving the alkalophilic performances of the Xyl1 xylanase from Streptomyces sp. S38: structural comparison and mutational analysis. Protein Sci. 14(2): 292-302.

de Oliveira, A.F., F. Rais, I. Dettori, M. Azzena, and G. Nieddu (2019). UV Light Acclimation Capacity of Leaf Photosynthetic and Photochemical Behaviour in Near-isohydric and Anisohydric Grapevines in Hot and Dry Environments. South Afr. J. Enol. Vitic. 40: 1-1.

Edziri, H., R. Jaziri, H. Chehab, L. Verschaeve, G., Flamini, D., Boujnah, M., Hammami, M. Aouni, and M. Mastouri (2019). A comparative study on chemical composition, antibiofilm and biological activities of leaves extracts of four Tunisian olive cultivars. Heliyon, 5: e01604.

Espenshade, J., S. Thijs, S. Gawronski, H., Bové, N. Weyens, and J. Vangronsveld (2019). Influence of Urbanization on Epiphytic Bacterial Communities of the Platanus $\times$ hispanica Tree Leaves in a Biennial Study. Front. Microbiol. 10: 675.

Gerhardt, P., R.G.E. Murray, W.A. Wood, and N.R. Krieg (1994). Methods for general and molecular bacteriology. American Society for Microbiology, 1325 Massachusetts Ave, Washington, DC.

Guo, G., X.H. Sun, X.Y. Qiu, M. Shimojo, and T. Shao (2014). Characterization of Two Lactic Acid Bacteria and Their Influence on Silage Fermentation of Napiergrass. P. Vet. J. 34(2): 170-174.

Koh, K.S., K.W. Lam, M. Alhede, S.Y. Queck, M. Labbate, S. Kjelleberg, and S.A. Rice (2007). Phenotypic diversification and adaptation of Serratia marcescens MG1 biofilm-derived morphotypes. J. Bacteriol. 189(1): 119-130.

Liaqat I, Pervaiz Q, S.J. Bukhsh, S.I. Ahmed, and N. Jahan (2016). Investigation of bactericidal effects of medicinal plant extracts on clinical isolates and monitoring their biofilm forming potential. P. Vet. J. 36(2): 159-164.
Liaqat, I., F. Sumbal, and A.N. Sabri (2009). Tetracycline and chloramphenicol efficiency against selected biofilm forming bacteria. Curr. Microbiol. 59(2): 212-220.

Miller, J.H. (1992). A Short Course in Bacterial Genetics. A laboratory Manual and Handbook for E. coli and Related Bacteria. Cold Spring Harbor Laboratory Press, Cold Spring Harbor, p. 150156.

Monier, J.M. and S.E. Lindow (2003). Differential survival of solitary and aggregated bacterial cells promote aggregate formation on leaf surfaces. PNAS. 100:15077-15982.

Müller, H., C. Berg, B.B. Landa, A. Auerbach, C. MoisslEichinger, and G. Berg (2015). Plant genotypespecific archaeal and bacterial endophytes but similar Bacillus antagonists colonize Mediterranean olive trees. Front. Microbiol. 6: 138.

O’Toole G.A. and R. Kolter (1998). Flagellar and twitching motility are necessary for Pseudomonas aeruginosa biofilm development. Mol. Microbiol. 30(2): 295-304.

Pointing, S.B., K.A. Warren-Rhodes, D.C. Lacap, K.L. hodes and C.P. McKay (2007). Hypolithic community shifts occur as a result of liquid water availability along environmental gradients in China's hot and cold hyperarid deserts. Environ. Microbiol. 9: 414-424.

Sharon, Y., G. Dishon, and S. Beer (2011). The effects of UV radiation on chloroplast clumping and photosynthesis in the seagrass Halophila stipulacea grown under high-PAR conditions. J. Mar. Biol. 2011.

Sinha, R.P. and D.P. Hader (2002). UV-induced DNA damage and repair: a review. Photochem Photobiol. Sci. 1: 225-236.

Yang, C.H., D.E. Crowley, J. Borneman, and N.T. Keen (2001). Microbial phyllosphere populations are more complex than previously realized. Proceedings of the National Academy of Sciences of the United States of America 98: 3889-3894.

Yang, S.S. and J.C. Zhou (2004). Growth and environmental factors of microbe. In: Microbial biology (ed. Zhang, H.) Science Press, Beijing. 